\title{
LA “COCINA” DE UNA INVESTIGACIÓN COLABORATIVA: ESCENARIOS, ESCENAS Y ALGUNOS ENSAYOS
}

\author{
A collaborative research's 'kitchen': \\ sceneries, scenes and some essays
}

\author{
Ana Dumrauf ${ }^{1}$ \\ Silvina Cordero ${ }^{2}$ \\ Adriana Mengascini ${ }^{3}$ \\ Cecília Mordeglia ${ }^{4}$
}

\begin{abstract}
Resumen: En este trabajo presentamos una experiencia de investigación en el área de educación en ciencias naturales, desarrollada colaborativamente entre integrantes de una universidad nacional y de instituciones educativas de diferentes niveles del sistema provincial. Específicamente, pretendemos analizar mecanismos puestos en juego durante el desarrollo de la etapa de conformación del equipo y apropiación del proyecto por las participantes. Desde el punto de vista teórico nos orientaron los estudios sobre formación docente situada y la sistematización de experiencias de investigación acción. Metodológicamente elegimos la narración de escenas y su análisis para la presentación de las categorías que construimos (negociaciones, escenarios, objetos y sujetos de negociación, actitudes y estrategias) y su discusión. Finalmente, reflexionamos acerca de los aprendizajes que conllevó la experiencia y sus análisis en función de una nueva "puesta en escena".
\end{abstract}

Palabras-clave: Investigación colaborativa. Negociaciones. Reflexión sobre la práctica.

\begin{abstract}
In this paper we present a collaborative research experience in Science Education between teachers of different educative levels. Specifically, we analyze the mechanisms which took place during group and project work by the participants. From a theoretical point of view we were guided by the teacher's education studies and the systematization of action-research experiences. Methodologically, we have chosen the narration of scenes and their analysis to introduce the obtained categories (negotiations, scenes, objects and subjects, of negotiations, attitudes and strategies) and the discussions the group had about them. Finally, we present a reflection about our own learning through this experience and its analysis, towards a new "mise-en scène".
\end{abstract}

Keywords: Collaborative research. Negotiations. Reflection about our own practice.

\footnotetext{
${ }^{1}$ Licenciada em Física. Doutora em Física. Docente, Facultad de Humanidades y Ciencias de la Educación, Universidad Nacional de La Plata. Argentina. <adumrauf@iflysib.unlp.edu.ar>

${ }^{2}$ Mestre em Educação (UFF). Docente, Departamento de Ciencias de la Educación, Universidad Nacional de La Plata, Argentina. <scordero@netverk.com.ar>

${ }^{3}$ Licenciada em Biologia. Especialista em Enseñanza de las Ciencias Experimentales. Docente, Facultad de Ciencias Naturales y Museo, Universidad Nacional de La Plata. Argentina. <adriamen@fcnym.unlp.edu.ar>

${ }^{4}$ Licenciada em Biologia. Docente, Facultad de Ciencias Naturales y Museo, Universidad Nacional de La Plata. Argentina.<cmordeg@fcnym.unlp.edu.ar>

${ }^{1}$ IFLYSIB-CONICET

Calle 59, n.789, cc 565

B1900BTE - La Plata

Buenos Aires, Argentina 


\section{Introducción}

A pesar de la existencia de cierta tradición al respecto, abrir la puerta de la "cocina" de un proceso de investigación continúa siendo una tarea desafiante, y hasta, podría decirse, peligrosa. Desafiante, por las actitudes de sinceramiento y autoanálisis que exige, a fin de no caer en la seducción de la autocomplacencia ni del autocastigo; peligrosa por el riesgo que implica revelar y colocar bajo la lupa pública, las aparentes o reales flaquezas y fortalezas de un proceso de trabajo. Dichas revelaciones podrían determinar su aceptación o exclusión del campo por incumplimiento de alguna de sus "normas".

Pero también constituye una tarea fascinante y necesaria, tanto para el propio proceso cuanto para el campo de investigación en educación en ciencias naturales. Dentro del mismo, creemos poder contribuir con algunas caracterizaciones y reflexiones a esa zona difusa que algunos rotulan como "formación docente situada", otros como "investigación colaborativa" y otros como "investigación-acción". Rótulos que nosotras - poniendo desde el principio sobre el papel una de las tensiones que nos envuelven - aún no decidimos si aceptar, pero que provisoria y operativamente nos permiten comenzar nuestra presentación.

En el año 2005 iniciamos un proyecto que se proponía "contribuir al mejoramiento de la calidad de la enseñanza de las Ciencias Naturales, a partir del desarrollo de una propuesta de investigación colaborativa sobre las prácticas de enseñanza en dicha área en EPB, ESB, Polimodal y Formación Superior ${ }^{5}$. En ella participarán docentes-investigadoras del Instituto Superior de Formación Docente No 168 de Dolores e investigadores universitarios de la Universidad Nacional de La Plata, que conformarán un equipo de trabajo a fin de construir conocimiento a partir de la reflexión crítica y creativa conjunta" (DUMRAUF, 2005a, p. 1).

"Investigación colaborativa", "reflexión crítica y creativa conjunta", fueron supuestos - y horizontes - teórico-metodológicos que elegimos para guiar nuestra mirada y delimitar nuestro camino desde el inicio. En el texto original, también especificábamos:

Considerando la importancia de la contextualización de la acción profesional docente y su carácter imprevisible y complejo, nos proponemos un trabajo colaborativo como posibilidad de ruptura con la racionalidad tecnicista. En el trabajo colaborativo, la reflexión y la intervención sobre la realidad se viabilizan a partir de la interacción entre pares que asumen papeles específicos en el proceso. (DOS SANTOS ROSA y PACHECO SCHNETZLER, 2003, p. 28 - traducción propia)

"Contextualización", "ruptura con la racionalidad tecnicista", "intervención sobre la realidad", "interacción entre pares que asumen papeles específicos" completaban nuestro marco de acción-pensamiento.

\footnotetext{
${ }^{5}$ EPB: Educación Primaria Básica (nivel obligatorio, abarca desde los 6 hasta los 11 años); ESB: Educación Secundaria Básica (nivel obligatorio, desde los 12 hasta los 14 años); Polimodal: corresponde a la Educación Secundaria Superior (desde los 15 a los 17 años); y Formación Superior (constituye la oferta educativa de nivel superior no universitario, desarrollada en los Institutos Superiores de Formación Docente).
} 
Como investigadoras en educación en ciencias naturales hace tiempo dedicadas al análisis de los procesos de enseñanza y aprendizaje en contextos "naturalistas", desde una perspectiva no intervencionista, deseábamos trabajar con docentes respecto de sus prácticas. Trabajar con, partiendo de un piso de mutuo reconocimiento de saberes. Pero también evidenciando naturalizaciones, rutinizaciones y empobrecimientos modificables. Acompañar en, y estimular, la generación de innovaciones respecto de las prácticas habituales, aún cuando estas novedades fueran mínimas. "Empoderamiento", dicen algunos (por ejemplo, SÁNCHEZ PILONIETA, 2002). Autoconfianza para enfrentar nuevos emprendimientos, aumento de la autoestima de las participantes y cambios en el clima institucional, pretendíamos nosotras.

Ese camino nos llevaría también a desnaturalizar nuestras propias prácticas investigativas. Nos enfrentamos, específicamente, al interrogante de cómo se concretizaría una investigación colaborativa. Las respuestas que encontramos inicialmente en la literatura no nos sirvieron. En el proyecto inicial planteábamos:

Aún cuando no existe un solo modelo o modo de llevar a cabo un proceso de investigación-acción y el diseño específico será desarrollado en el marco de la investigación colaborativa, diversos autores (BOGGINO y ROSEKRANS, 2004; ELLIOT, 1994) acuerdan en identificar las siguientes fases:

. la identificación de un problema y la delimitación del tema;

. la definición de los propósitos;

- la construcción del marco teórico;

- la elaboración de las preguntas de investigación y de las hipótesis de acción;

- la elección de métodos y recursos de investigación;

- la definición de los acuerdos de validez de los resultados; y

. la construcción de un marco ético.

Estas fases se reiteran en ciclos que las abarcan en su totalidad o parcialmente. (DUMRAUF, 2005b, p. 17)

Nuestras imágenes del proceso desarrollado poco se aproximan a las fases establecidas por la literatura en el campo. Y se distancian fundamentalmente por desconsiderarse una etapa que para nosotras implicó el trabajo de más de un año: la conformación del equipo y la apropiación del proyecto por las participantes.

Este trabajo pretende develar algunos mecanismos puestos en juego durante el desarrollo de esta etapa del proceso de investigación colaborativa. Negociaciones, actitudes y estrategias, son los nombres - categorías de análisis - que en su reconstrucción nos inspiraron. Pero antes, hace falta presentar nuestros referenciales teóricos, las características de esta experiencia y nuestra metodología de trabajo. 
Dumrauf, A. et al.

\section{Referenciales teóricos}

Localizamos nuestra investigación en el campo de los "estudios sobre formación docente" (ACHILLI, 2004). Respecto de nuestra modalidad de trabajo

Acordamos con el principio, suscrito en varias de las investigaciones sobre la formación docente, de la potencialidad contenida en la reflexión acerca de la práctica: ésta es tanto una manera de investigar como una modalidad de enseñanza y aprendizaje y un camino para la revalorización social del trabajo docente [...] Ante esta situación, una propuesta sencilla emerge: crear condiciones para que los educadores, agrupados en sus espacios de trabajo y acompañados por profesionales que suscriben una visión crítica y ampliada de la ciencia, la investigación y la formación docente, se hagan cargo de sus discursos, miren sus prácticas y muestren sus operaciones, sus logros y caídas a sus estudiantes [...] «es posible transformar las prácticas pedagógicas de la escuela, si se generan los espacios institucionales necesarios para reflexionar acerca de los supuestos que las sustentan» $[\ldots]$. Se requiere para ello una disposición individual favorable a la crítica y a la aceptación de la incertidumbre y la propia vulnerabilidad, que, a su vez, necesita de una sociedad democrática y respetuosa de la diversidad y del espacio del otro. (MESSINA, 1999, p. 165-66)

El trabajo colaborativo que nos propusimos, a través del cual fuimos delineando y poniendo en práctica actividades de formación docente, poseía puntos de contacto con lo que algunos autores han denominado "investigación-acción". Como dicen Freitas Petrucci y otros (2003, p. 7):

La investigación-acción se ha configurado como una forma de trabajo colectiva bastante importante basada en la epistemología de la práctica. $[\ldots]$ la investigación-acción ofrece una oportunidad de articulación entre teoría y práctica, que promueve la emancipación de los sujetos involucrados, a través de la interlocución, donde todos son participantes. (traducción propia).

El diálogo, la interlocución, la participación constituyeron supuestos, y al mismo tiempo, desafíos inherentes a la puesta en práctica de procesos tanto de investigación-acción cuanto de formación docente basados en la reflexión sobre la práctica.

Como dice Freire (2002b, p. 216)

La colaboración, como característica de la acción dialógica, la cual sólo se da entre sujetos, aunque en niveles distintos de función y por lo tanto de responsabilidad, sólo puede realizarse en la comunicación. El diálogo, que es siempre comunicación, sostiene la colaboración [...]. El diálogo no impone, no manipula, no domestica, no esloganiza. 
El proceso de trabajo, dada su complejidad y dinámica, tuvo sus momentos de confusión, incertidumbre, tensión, conflicto y reformulación. También de desilusión, alegría, satisfacción, frustración y esfuerzo.

Nos pasó, entre otras cosas, lo mismo que a Pereira dos Santos y otros (2006, p. 10):

El gran desafío del proyecto [...] realizado conjuntamente con profesores de enseñanza media, es la constante negociación entre la propuesta de nuevas metodologías y la tendencia de los profesores a reproducir concepciones de enseñanza consagradas en el aula, aun cuando fueran conflictivas con las nuevas propuestas. Eso significa que el principio de la investigación sobre la acción, respetando el contexto cultural, implica una opción metodológica que, si por un lado viabiliza la aceptación e inserción de nuevas propuestas en el contexto educacional, por otro implica una negociación, en la que no siempre las propuestas idealizadas, en los moldes de los principios de la investigación [...] son las predominantes. (Traducción propia)

¿Qué se pone en juego en esas negociaciones?

Un campo no muy reconocido de la investigación de la acción social, la "sistematización” de proyectos sociales y educativos, pareció poder darnos algunas respuestas.

A través de [la sistematización] nos interesaba identificar el modo en que se relacionan esos saberes distintos, esos actores diferenciados, la manera como estos interpretan lo ocurrido y los modos de legitimación que instituye cada proyecto [...]. De este modo, la sistematización al igual que las experiencias a analizar, se convierte en una negociación cultural; un cruce de interpretaciones, saberes y lógicas entre los diversos actores y los investigadores cuyo proceso y resultado hablan de las condiciones y modos en los que se da este juego de fuerzas. Esta confrontación de horizontes interpretativos no sólo posibilita construcción de conocimiento, sino también producción de sentido y logros de aprendizajes para sus participantes. (TORRES CARRILLO, 1996, p. 14)

"Negociación cultural", "confrontación de horizontes interpretativos", tensiones. Durante el desarrollo del proyecto hemos ido vivenciando diversas tensiones, que fueron planteando constantes negociaciones hacia el interior del equipo y en relación con el espacio institucional, emergiendo distintas estrategias y actitudes en la negociación. Hablamos de estrategia en referencia a las alternativas de acción portadoras de una intencionalidad - no siempre explícita, ni consciente - que, en el vínculo entre sujetos, hemos desplegado, basadas en un análisis contextualizado de la situación y de los recursos disponibles. En cuanto a las actitudes, Coll et al. (1992, p. 137) las definen como "Tendencias o disposiciones [...] a evaluar de un modo determinado un objeto, persona, suceso o situación y a actuar en consonancia con dicha evaluación". 


\section{Descripción general de la experiencia}

A fines del año 2005 comenzamos el proceso de constitución del equipo de investigación, pero fue durante el año 2006 que logramos conformarlo. El equipo se compone de un grupo coordinador en el que participamos las autoras de este trabajo, docentes-investigadoras de la Universidad Nacional de La Plata y tres docentes del Instituto Superior de Formación Docente $\mathrm{N}^{\circ} 168$, perteneciente a la Unidad Académica "Victoriano E. Montes", de la ciudad de Dolores ${ }^{6}$. Integraron inicialmente también el equipo de trabajo cuatro maestras de educación primaria básica (EPB), tres profesoras de educación secundaria básica (ESB), cinco de educación media y una profesora y dos estudiantes de la carrera de Profesorado en Ciencias Naturales del Instituto Superior de Formación Docente. Todas estas docentes pertenecen a las instituciones de gestión pública que constituyen la Unidad Académica Victoriano E. Montes.

El equipo coordinador trabajó semanalmente en Dolores y/o La Plata, discutiendo líneas de acción, planificando y coordinando los encuentros con el equipo completo, organizando y evaluando las actividades formativas con especialistas invitados (dos conferencias y un taller), elaborando materiales de trabajo en base a la sistematización de la producción de los encuentros y materiales teóricos, y redactando proyectos para el financiamiento de la experiencia que se presentaron ante diversos organismos.

El equipo completo de docentes se reunió cinco veces durante el año 2006. En estas reuniones trabajamos acerca de nuestras expectativas sobre el proyecto y comenzamos a delimitar las temáticas a abordar en las aulas; constituimos subgrupos de trabajo; analizamos teóricamente la metodología de taller y pusimos en práctica uno (acerca de las Leyes de Newton), revisando la experiencia a la luz del material teórico; y finalmente, realizamos un balance del trabajo del año y delineamos su proyección. También implementamos encuentros con cada uno de los cuatro subgrupos de trabajo que se constituyeron, los cuales, a su vez, se reunían extra-escolar e independientemente de nuestra participación para la elaboración de sus propuestas. En las reuniones con los subgrupos profundizamos en aspectos conceptuales de las problemáticas a abordar en las aulas, discutimos el diseño de las planificaciones de clase y establecimos las formas de registro.

Como producto de todo este proceso se diseñaron e implementaron tres propuestas didácticas y se definió la realización de la sistematización de una propuesta ya implementada (referida a "Reproducción Humana" en $1^{\circ}$ año de la ESB). Las propuestas didácticas diseñadas e implementadas fueron: "Taller de reciclado de papel", implementadas por las maestras de la EPB; "Taller sobre los dilemas éticos vinculados al Proyecto Genoma Humano", actividad desarrollada por las profesoras del ISFD y una docente de la EEM, con estudiantes de $2^{\circ}$ a $4^{\circ}$ años del Profesorado en Ciencias Naturales; y por una de las docentes de la EEM y una de las estudiantes participantes en el proyecto con estudiantes de $2^{\circ}$ año de Polimodal; y "Taller de ondas" actividad desarrollada con estudiantes de $2^{\circ}$ año del nivel Polimodal. Las tres propuestas didácticas diseñadas e implementadas pueden caracterizarse, de manera esquemática, como compuestas por tres momentos: la explicitación de ideas previas de los estudiantes respecto a la temática abordada; la concreción de una tarea grupal (en pequeños grupos) ten-

${ }^{6}$ Ubicada a unos $200 \mathrm{Km}$. de la ciudad de La Plata (Provincia de Buenos Aires, Argentina). 
diente a la elaboración y análisis de un producto (tecnológico o de conocimiento); y la puesta en común del trabajo grupal y el aporte teórico de las docentes.

\section{Algunas cuestiones metodológicas más específicas}

Partiendo del marco ya explicitado de investigación colaborativa, uno de los aspectos consensuados con las participantes fueron las formas de registro para cada actividad desarrollada. Por ello, los instrumentos para el registro fueron diversos: notas de campo de todas las instancias y de dos propuestas áulicas implementadas; grabaciones en audio de las reuniones del grupo coordinador y de una de las propuestas didácticas; y videograbaciones de las reuniones del equipo de trabajo y de dos de las propuestas áulicas.

Con relación a la información presentada en este artículo, el trabajo de análisis que hemos desarrollado las autoras requirió, en una primera etapa, de una lectura completa de toda la información relevada y de la realización, en forma paralela, de una revisión bibliográfica específica, respecto de trabajos que abordaran procesos de investigación de características similares. Ambas actividades orientaron, en una segunda etapa, la elaboración de categorías teóricas (negociaciones, sujetos y objetos de negociación, actitudes y estrategias), la relectura de los registros y la selección de episodios. A partir de la transcripción de los mismos y nuestra interpretación general del proceso, definimos escenarios de negociación y construimos escenas que pretenden sintetizar algunos rasgos caracterizadores de las estrategias y actitudes presentadas.

La narración de escenas constituye un dispositivo poco convencional en los artículos de investigación en didáctica de las ciencias naturales.

Entendemos como narrativa la cualidad estructurada de la experiencia entendida y vista como un relato; por otro (como enfoque de investigación) las pautas y formas de construir sentido, a partir de acciones temporales personales, por medio de la descripción y análisis de los datos biográficos. Es una particular reconstrucción de la experiencia, por la que, mediante un proceso reflexivo, se da significado a lo sucedido o vivido. (BOLÍVAR BOTÍA, 2002, p. 44)

Las escenas elaboradas constituyen “instantáneas”, imágenes estáticas que destacan algunos rasgos relevantes en los procesos vividos. Por esto, si bien presentan la limitación de no evidenciar las mutaciones o fluctuaciones que toda trama vincular y proceso grupal implican, nos permiten caracterizar un recorte particular de los mismos (que denominamos negociaciones, actitudes y estrategias).

\section{Escenarios, sujetos y objetos de negociación}

Fueron objetos de negociación: los roles a asumir en el marco del proyecto, los tiempos y espacios dedicados a él, las condiciones de realización, la conformación de equipos de trabajo, las expectativas de las participantes, las formas de realizar investigación en educación, entre otros. 
Fuimos sujetos de negociación: las integrantes del equipo coordinador; todas las integrantes del proyecto; las instituciones involucradas.

Frente a lo que se presentaba como una tensión, las protagonistas del proceso fuimos tomando diversas actitudes, que bien podían facilitar la negociación como obstaculizarla o dejarla fuera de consideración. Para nosotras, como coordinadoras, hubo cosas negociables... y no negociables. Así, negociamos y renegociamos constantemente los días y horarios de encuentro, entre las participantes y con la institución (y los diversos niveles de la misma), pero en ningún momento se puso a negociación la continuidad del proyecto mismo. Buscamos alternativas para comenzar a trabajar en conjunto, colaborativamente, construyendo una representación de "lo posible", analizando aquello de nuestras prácticas que considerábamos deseable y posible de modificar. Pretendimos, a través de las reuniones del equipo de trabajo completo y en los encuentros con los subgrupos, construir nuevas formas de vincularnos, romper con el lugar de "poseedoras del saber" por provenir de la universidad. Para ello, explicitamos sueños y temores. Compartimos vivencias y expusimos marcos teóricos y metodológicos. Vivimos, como equipo de investigadoras universitarias, un proceso de inmersión en el contexto escolar, en el que debimos aprender a vincularnos con las prácticas, saberes, dificultades y deseos de nuestras compañeras docentes, hasta sentir que "su casa" comenzaba también a ser nuestra. Conocimos y dimos a conocer, hasta apropiarnos recíprocamente, las diversas lógicas institucionales, tanto de nuestras prácticas docentes como de investigación.

Durante este proceso, algunas integrantes del grupo inicial se desvincularon del proyecto. En la actualidad, conformamos el equipo de trabajo doce docentes-investigadoras y una estudiante del profesorado.

Las tensiones con las instituciones fueron diversas y constantes. Dentro de la institución escolar surgieron dificultades ya que sus tradiciones no prevén el trabajo colaborativo y el desarrollo de investigaciones por los propios docentes. El funcionamiento escolar habitual no favorece que maestras y profesoras se reúnan para reflexionar, proponer innovaciones, trabajar en grupos. Por otro lado, algunos autores han hipotetizado que la estabilización de procesos de trabajo autónomos dentro de la escuela necesitan la aprobación y el efectivo apoyo institucional (BARCELOS y VILLANI, 2006). En este sentido, resultó vital en nuestra experiencia, para encontrar una salida a esta tensión, el trabajo incesante de la vicedirectora de la Unidad Académica, integrante del equipo coordinador, quien negoció con el resto de las autoridades, y logró la autorización de espacios de encuentro en los horarios de clase de las docentes. Esto implicó movimientos adicionales en las instituciones. En el caso del nivel Superior, docentes de diferentes materias cedieron algunos espacios que posibilitaron la realización del taller vertical sobre el Proyecto Genoma Humano mencionado, con alumnos de tres años del Profesorado en Ciencias Naturales. En el caso del nivel Primario, la gestión inicial de la vicedirectora fue tomada y sostenida por el grupo de maestras participantes del proyecto quienes "crearon" sus propios espacios de encuentro. Este movimiento comprendió a docentes no participantes del proyecto: profesores de educación física, música, inglés quienes frecuentemente intercambiaron horarios para que las maestras dispusieran de tiempos para reunirse. Así, estas docentes lograron implementar formas de trabajo inusuales en los establecimientos primarios de gestión pública, no sólo consiguiendo momentos de planificación y reflexión, sino también tomando a su cargo la coordinación conjunta y el registro mutuo del "Taller de reciclado de papel”, replicado en cada una de las secciones a su cargo. Uno de los mayores 
logros de este grupo de trabajo fue el de constituirse en "creador de escenarios" institucionales que posibilitaron y potenciaron acciones y reflexiones colectivas.

Las tensiones con las instituciones universitarias y con los organismos de financiamiento a la investigación, en gran medida, no se evidenciaron en el día a día concreto sino en las instancias de evaluación periódica. Sin embargo, las autoras de este trabajo sentimos constantemente la presión de las pautas establecidas, que en general no acuerdan con los tiempos ni con las modalidades de desarrollo de una investigación colaborativa. En particular nos referimos a las reformulaciones imprescindibles al plan de trabajo inicial y al tiempo que requiere este abordaje para llegar a una producción "publicable". Este proceso también implicó negociar, con nuestros estudiantes y compañeros de trabajo en la universidad, modificaciones en los cronogramas de clase y reemplazos para ajustar nuestros tiempos a las posibilidades del resto de las integrantes del equipo.

\section{Escenas de negociación: actitudes y estrategias frente a la tensión}

Las cinco escenas que presentamos a continuación ilustran algunas estrategias y actitudes adoptadas por diferentes participantes durante el trabajo conjunto. En nuestra reconstrucción del proceso, dichas actitudes y estrategias aparecieron como las más frecuentes y características. Como estructura de presentación, elegimos relatar las escenas - que incluyen fragmentos de conversaciones y nuestras sensaciones, pensamientos y decisiones en la acción - comentar su contenido, interpretando lo sucedido y adelantar en líneas generales el proceso seguido por las participantes implicadas con relación al proyecto.

\section{Escena 1: Un ejercicio de persuasión}

En escena: Una docente de ESB (Dora ${ }^{7}$ ), una estudiante del Profesorado en Ciencias Naturales (Nuria), y tres integrantes del equipo coordinador (Andrea, Sonia y Analía).

Estamos en reunión con uno de los subgrupos de trabajo, en la etapa de delimitación de temas y planificación de propuestas de aula.

Dora comenta el desarrollo de la parte de su programa anual que refiere a Reproducción, plantea que hace mucho que da las clases de esa manera y que le sale bien, que los chicos toman el tema seriamente y le tienen confianza. ¿Qué proponer, entonces, si la docente no expresa claramente ninguna necesidad de cambio? ¿Qué es lo que ella espera de las coordinadoras y del proyecto?

Andrea lo explicita en voz alta: "no me siento en condiciones de proponerte una actividad" "Porque [si fueras] alguien que dice "no me animo a trabajar con sexualidad', o 'lo trabajo así pero no estoy conforme'...Pero acá parece que [...]

\footnotetext{
${ }^{7}$ A fin de preservar la identidad de las participantes hemos reemplazado los nombres de pila por seudónimos.
} 
Dumrauf, A. et al.

funciona, que los chicos se enganchan, que todas las cosas que queremos buscar para las experiencias están funcionando. Entonces, ¿qué te aportaría, qué podríamos hacer?".

"iAy, aporten! A que me aporten, a eso vengo", dice Dora.

Sonia aporta la idea de un taller sobre sexualidad "donde habían trabajado, antes de abordar el contenido formalmente, con las imágenes que ellos [los estudiantes] tienen de lo que es el aparato reproductor, masculino y femenino. O sea, tenían que armar con frutas y verduras [...] como una especie de maqueta de cómo ellos se imaginaban que era el aparato reproductor femenino y masculino. Un modelo, porque es un modelo [...] Como una posibilidad diferente de abordaje, no partir de darles la información, sino de ver con qué representación vienen y cómo se imaginan que es el cuerpo, su cuerpo, antes de decirles cómo es desde el punto de vista anatómico".

Dora asiente. Se queda pensando y cuenta que cuando podía usar la sala de informática ("en la época en que andaban las computadoras") les mostraba a los chicos una animación del ciclo menstrual, luego de haber visto el tema en el aula. A los chicos les gustaba.

"Yo lo que quiero es que alguien me diga de qué manera puedo, de qué otra manera abordarlo, o qué otra sugerencia ¿viste?"

"Por ahí no es otra forma de encararlo, por ahí es, pensar en decir, bueno, hagamos un registro [...]" dice Andrea. La propuesta va tomando forma: no proponer cambios, sino presentar el modo en que aborda el tema habitualmente. Es decir, hacer una detallada sistematización de las clases de Dora sobre Reproducción con estudiantes de $1^{\circ}$ de ESB. Esto permitiría presentar el caso a otras docentes, por un lado, y analizar con más detalle los recursos, acciones, respuestas y demás procesos que se van dando en clase.

Dora duda.... no dice nada pero parece que los argumentos de Andrea no la convencen.

Nuria podría ir a observar las clases, los chicos ya la conocen y no provocaría distracciones su entrada al aula. Con Dora ya se conocen y tienen confianza. "¿Qué te parece? ¿Te parece que esto te puede aportar?" pregunta Andrea. "Sí, yo voy a mostrar lo que hago". "Claro".

De cualquier modo no parece convencida, se queda pensando y expresa "capaz que tendría que haber elegido otro tema [...] no sé, otra cosa, en la que ustedes pudieran..."

Andrea: "¿Sabés que me parece que en todos los temas te iba a pasar esto? Porque vos no sos una profesora improvisada, vos todos los temas los tenés pensados, repensados, sacado el jugo, probado, re-probado..."

Nuria apoya esto comentando que Dora siempre tiene propuestas, opciones y recomendaciones para dar a los que recién se inician, lo que Dora reconoce como "eso te hace la experiencia". "La experiencia y la búsqueda, porque vos estás permanentemente buscando revistas, libros, cursos, talleres", agrega Andrea. Pero Dora no sabe hasta dónde seguir con tantos cursos y demás, "porque no sé si saco demasiado nuevo ¿viste?" 
Andrea argumenta entonces que "Me parece que además de lo que te pueden dar, hay muchas cosas que vos podés dar a otros".

Sonia y Analía siguen pensativas y silenciosas la charla. Ven a Dora poco convencida con la propuesta, pero tampoco logran aportar nada diferente.

Frente a una demanda difusa de Dora, nuestra primera acción como coordinadoras consistió en tratar de clarificarla: ¿Qué te podríamos aportar? Su requerimiento de propuestas condujo a la segunda acción: ofrecimos una alternativa concreta, pero muy diferente de su modo de trabajo habitual en clase. Dora no pareció considerarla. Explicitó una actividad que en algún momento consideró exitosa y que ya no puede implementar por causas externas (ya no se dispone del recurso informático). La clase pareció haberse convertido en un objeto no negociable. Y Dora se colocó nuevamente en una posición de demanda: "Yo lo que quiero es que alguien me diga de qué manera puedo, de qué otra manera abordarlo, o qué otra sugerencia". Ante esta aparente contradicción, Andrea decidió cambiar el eje de la negociación: la clase no se modificaría, el trabajo sería registrarla y sistematizarla para su comunicación a otros docentes. Hasta sugirió la forma de registro: Nuria, ya conocida por el curso y por la docente, podría observar la unidad y realizar un registro escrito.

Tampoco esta opción pareció convencer a Dora. Su nueva acción de resistencia pasó por considerar que nosotras no podíamos aportarle sugerencias en ese tema, y que "tendría que haber elegido otro". Frente a este comentario, que podría haber sido valorado como descalificatorio, Andrea mantuvo la estrategia de persuasión: reconoció los méritos y la experiencia de Dora y aceptó los límites puestos tácitamente por ella a su intervención. Insistió en su posibilidad de aportar a otros, más que en la de recibir aportes, lo cual reforzó el cambio de eje en el proceso de negociación.

En síntesis, Dora se presentó con una actitud de resistencia, tanto al cambio (utilizar otro abordaje) como a la propuesta de registrar lo que efectivamente hacía (tal vez porque se sintiera "observada", en el sentido de cuestionada); en esta escena explícitamente aceptó que se realizara la observación. Nuria elaboró un registro escrito de sus clases. Sin embargo, más tarde, Dora se retiró del proyecto sin iniciar la sistematización de la información obtenida.

\section{Escena 2: La resistencia al cambio ${ }^{8}$ y su superación}

En escena: Tres docentes de EEM y Polimodal (Isabel, Melina y Celia) y dos de las coordinadoras (Andrea y Mora)

Isabel trata de armar un taller sobre "Ondas" para aplicar las innovaciones propuestas desde el proyecto. Tiene a mano un taller sobre el tema diseñado por Sonia para profesores... Quiere trabajar con Melina y Celia en la planificación y puesta en práctica de sus propuestas, pero ellas, sin ser muy explícitas en sus objeciones, no parecen dispuestas a acompañar su intención.

\footnotetext{
${ }^{8}$ Desde el marco teórico de la psicología social de Pichon-Rivière (1985) esta resistencia al cambio podría interpretarse como manifestación de los dos miedos básicos: a la pérdida de lo conocido y al ataque de lo nuevo. No hemos utilizado este marco teórico en nuestro análisis, ya que no nos centramos en el estudio de la matriz vincular del equipo de trabajo ni en su proceso grupal desde el punto de vista psicológico.
} 
Dumrauf, A. et al.

Una de las opciones que se le ocurre a Isabel, por donde podría pasar la cooperación entre las tres docentes, es la de armar material didáctico en kits que puedan usar todas con sus grupos de alumnos.

Isabel va pensando en voz alta sobre los materiales disponibles/necesarios para implementar el taller. Lo compara con el taller sobre las Leyes de Newton que vivenciaron unas semanas antes, como parte de las actividades de actualización docente ofrecidas en el marco del proyecto.

Dice que tiene material para trabajar con sus alumnos, divididos en 7 grupos, pero que es todo distinto. Andrea replica que no es necesario que todos los grupos trabajen con el mismo material, ni que hagan todos exactamente lo mismo; incluso agrega que "a lo mejor es más productivo que cada uno [...] trabaje en una cosa distinta y después se ponga en común y se aprovecha un poco de cada uno".

Isabel duda, cavila. Relee la propuesta de taller de Sonia (que "no está tan fea", aunque Andrea le dice que era una muestra, no para seguir cual receta) como para ir basándose en algo. Lee en voz alta algunas de las consignas y la técnica de armado de grupos. Pide ayuda a sus compañeras "No sé, chicas. Propongan ustedes...". Nadie acude, salvo Andrea, con la que ya viene conversando.

Quedan en que el tema podría desarrollarse en una clase o dos, no más. Pero para ella el material sigue siendo el problema... "Pero yo tengo todo de a uno ¿eh? Es lo [...] que me pasa con la película Apolo XIII que ya le falta el final, como no consigo la llave no pueden ver el final. O como tengo de a una hora, ya ni ganas tengo [...] se te va el entusiasmo ¿viste?".

Como la ve dubitativa, Andrea le dice que no se sienta presionada para hacerlo, que "podés acompañar a las chicas, si lo hacen, o si sólo lo hace Melina, una la observa una clase, otra la observa otra. Pero me parece que no nos tenemos que exigir más". "No, no, no", dice Isabel, y "me parece que no tenía muchas ganas tampoco Melina".

Andrea insiste en que "a mí me parece que cuando se transforma en algo, que es más incómodo que cómodo, no sirve. No te sirve a vos [...] y no te vas a sentir cómoda y no, no va a ser productivo". Igual propone "a lo mejor se puede achicar todo un poquito más. El trabajar con esto de las ideas [previas de los estudiantes]. Tal vez sin [trabajar con] la experiencia. Corto. Breve. Ahí hacer como una exposición teórica de las características [de la onda]. Y después, si seguimos trabajando con los tipos [de ondas], ahí sí, que los grupitos tomen los resortes y las sogas y se vea el tema de los tipos de ondas y qué pasa cuando pasan de un medio a otro. Que eso también te sirve para luz, no por similitud de onda, pero sí que hay cosas que cambian cuando pasa de un medio a otro. [...] Que para la luz también te va a servir esa idea. No te va a servir la onda mecánica. Y... y eso es todo. Digamos, y después, bueno, habrá que hacer todo el cierre teórico, rescatar..."

Isabel sigue con la lectura de la planificación del taller de Sonia, a la vez que se responde a sí misma: "Porque por ejemplo, acá, el grupo uno y tres yo había 
copiado esto que decía: longitud de onda y amplitud [...] Muy bien, generar ondas que viajen por el resorte, estos dos grupos, cada grupo tendrá su resorte. ¿Cómo distingo una onda de otra? No sé si las van a saber distinguir ¿cómo las van a distinguir? Si estiro más el resorte ¿qué propiedad de la onda cambia? Eso sí. Si agito el resorte más suave o más intensamente ¿qué propiedad de la onda cambia? Bueno". Habla consigo misma...

Andrea intenta recapitular algo del fundamento de tal actividad (diferenciar las ondas longitudinales de las transversales, según cómo se mueva el resorte). Isabel comenta la modalidad que solía utilizar para estas temáticas: "Yo, en estas clases que daba sonido, empezaba trayendo una cajita que le llamamos la caja negra, aunque es de cualquier color, que adivinaban qué había adentro...por el sonido. Después con este resorte [...] y una soga [...] les hacía hacer las ondas con la soga o con el resorte que para la longitudinal, como es largo el resorte, se ponían en el piso... uno de una punta, otro de otra, amontonaba el resorte, entonces el resorte iba y venía... y era longitudinal. [...] Y yo tengo en un rotafolio que dice si la onda va por arriba y viene por abajo, o va por arriba y viene por arriba...".

Mora, silenciosa hasta ese momento, resume el problema "Pero entonces lo tenés como muy armado. Lo que te cuesta es desarmar lo que tenés".

La docente que protagonizó esta escena, junto a las integrantes del equipo coordinador, puso de manifiesto sus resistencias al cambio arguyendo diversas preocupaciones: la falta de material suficiente para reproducir las mismas experiencias con los distintos grupos de alumnos simultáneamente; las dificultades que tendría para poner en práctica la planificación elaborada por otra persona; la pérdida del entusiasmo generada por los múltiples obstáculos que ha debido superar cuando quiere utilizar materiales inhabituales; y la ausencia de "ganas" en sí misma y en otras integrantes del equipo (en su frase "me parece que no tenía muchas ganas tampoco Melina”, el tampoco resultó revelador). La explicitación, al final de la escena, de su modalidad habitual de abordaje de la temática ofreció a Mora la clave de su dificultad: "Pero entonces lo tenés como muy armado. Lo que te cuesta es desarmar lo que tenés". Lo que le costó, pero finalmente logró, fue pensar su práctica áulica de una manera un tanto diferente de lo que venía haciendo desde muchos años atrás.

La escena muestra una negociación entre Isabel y dos de las coordinadoras, la primera tratando de ver alguna salida pero en el fondo resistiendo, y las otras sosteniendo una estrategia persuasiva, buscando proponer opciones y aligerar presiones. Aún cuando en esta escena no parece resolverse la tensión, la continuidad del trabajo conjunto, el compromiso de la docente con las coordinadoras y con el proyecto y el vínculo de respeto mutuo establecido le permitieron superar sus resistencias y elaborar una propuesta propia. Dicha propuesta mantuvo algunos rasgos de su práctica habitual e incluyó tanto sus iniciativas como algunas de nuestras sugerencias, tales como el relevamiento de concepciones previas de los estudiantes, el trabajo en subgrupos en el desarrollo de experiencias y el cierre teórico a partir de sus producciones.

La resistencia al cambio percibida inicialmente no sólo fue superada por esta docente a través del trabajo conjunto, logrando el desarrollo de una propuesta de aula innovadora, sino también su posterior análisis y la consecuente reformulación de la misma. En este proceso, 
Dumrauf, A. et al.

Isabel poco a poco fue animándose a exponer sus prácticas, a someterlas al análisis de otras compañeras y a recibir sus comentarios y sugerencias. De todo el equipo de trabajo fue la única que implementó, al año siguiente, la propuesta reformulada acompañada por una de las coordinadoras, quien elaboró nuevos registros de observación y fotográfico.

Escena 3: Resistencias y autoexclusión

En escena: tres docentes (Isabel, Celia y Melina) y dos coordinadoras (Andrea y Sonia)

La reunión del subgrupo de planificación de Talleres sobre "Ondas" hace rato que comenzó. Toda la primera parte fue una lectura y discusión acerca de la posibilidad de usar la planificación de otro Taller de Ondas elaborada por una de las integrantes del grupo coordinador y la idea de Isabel acerca de armar kits con materiales para experiencias que se pudieran usar con un número grande de participantes. La larga propuesta armada conjuntamente por el subgrupo (Isabel, Celia y Melina) la primera vez que discutieron sobre el tema, no las convencía, no sabían cómo llevarla al aula. En un momento de indefinición, la conversación deriva hacia cuándo se harían estos talleres y Celia plantea en cuánto tiempo sería conveniente hacerlo "Porque de acuerdo al tiempo, es lo que nosotros vamos a utilizar de todo eso". Andrea responde que eso lo tienen que definir ellas y que "a lo mejor no todas hacen lo mismo en el mismo tiempo". Celia interpone su preocupación: “...porque yo no sé cómo me va a ir con la experiencia, por el diseño que tengo en el salón, la cantidad de alumnos". Isabel se suma a la preocupación por el número de alumnos: “... son $37, y$ están apiñados en las mesas". Sonia señala que entonces no se les pueden proponer cosas que signifiquen mucho movimiento, a lo que Celia agrega que además "la mitad de los bancos son fijos". A pesar de sus objeciones, Celia explica que ella pensó "en hacerlo el viernes, por ejemplo, que yo tengo 2 horas y que son las 2 últimas horas. Entonces el ordenamiento no me iba a importar, ihasta eso había pensado!".

Una vez resuelta la cuestión del ordenamiento del aula y la posibilidad de que el taller dure más de una clase, Andrea plantea que sería "interesante que, de todo ese listado [de temas a abordar], me parece que la primera actividad, sería hacer un recorte". Celia asiente: "Con la parte que te interese". Isabel amplía la posibilidad: "Sí, que les interese y que se sientan más cómodas". Andrea acuerda y hace una propuesta concreta de trabajo: "Sí, que se sientan más cómodas y además teniendo en mente el resto, que no quiere decir que todo lo demás no se va a trabajar. $O$, a lo mejor, hay cosas de éstas que ustedes ya definen que no las trabajan este año ¿no? Pero hacer un recorte de contenidos, una jerarquización y como empezar a apuntar a la selección. Bueno, yo, ¿qué quiero trabajar? ¿Quiero hacer un disparador y dar los conceptos básicos de las ondas? ¿Quiero llegar hasta relacionar la altura con tal cosa? [...] Empezar a pensar como más concretamente sobre los contenidos y los objetivos de trabajo, y hasta dónde llega cada una. Que lo pueden discutir las 
tres pero, a lo mejor, después hasta dónde llega cada una, no va a ser igual. Y el tiempo que le va a dedicar a lo mejor tampoco. Pero como para empezar, porque es difícil pensar las actividades [...] concretas, si no sé qué contenidos quiero trabajar y cuáles objetivos. Claro, porque es bárbaro imaginarse actividades, pero después por ahí no te cabe ninguna".

Isabel sigue insistiendo en el armado de un kit de objetos para hacer actividades en grupos, pero Celia se preocupa por otra cuestión: “¿Se le puede pedir colaboración a alguno de los chicos del Profesorado para que te ayude?". Si bien acuerda, Isabel continúa con su preocupación: "primero, por la clase en sí, [...] a mí me cuesta pensar, si bien hacemos todo en el Gabinete con lo que hay, para cualquier parte de sonido, qué podemos multiplicar".

Un largo fragmento de la conversación se destina a explicar cómo utilizar resortes o sogas para representar ondas transversales y longitudinales. Andrea señala la dificultad del tema: "Viste que muchas veces uno, yo me acuerdo cuando me explicaban onda, la longitudinal siempre fue un misterio, porque no me terminaba de dar cuenta, no te terminás de dar cuenta cuál es la longitudinal, ¿no? Porque como es más difícil de representar" Sonia se expone: "Para mí esto es chino ¿eh? yo estoy diciéndoles las cosas que me explicaba la física". Celia también: "No te creas que para mí también".

La conversación se deriva hacia la presentación de bibliografía traída por las coordinadoras sobre propuestas de enseñanza acerca de la luz y la planificación, que ya se venía comentando, realizada por una de ellas en otro ámbito. Sonia explica que "es otro tipo de onda [la electromagnética], no se puede aplicar el mismo análisis, [hay que] introducir otro modelo". Celia nuevamente se expone: "Por eso yo nunca llego". Isabel, al mismo tiempo, señala que la luz a los alumnos les cuesta bastante, mientras Celia continúa evidenciando su dificultad con el tema: "De más está decirte que toda la parte de física la dejo para fin de año". Andrea cree que se refiere a la dificultad de los alumnos por la abstracción que implica el tema, pero Sonia percibe que ella lo está planteando desde su propia dificultad "No por los chicos, por vos". A lo que Celia asiente, pero aclara que "en principio puedo hablar de sonido y de onda". Sin embargo, más adelante en la conversación, hablando de cómo planificarían el taller, Celia explicita, riéndose: "Estoy pensando seriamente en cambiar de tema". Andrea plantea cambiar de planificación y Sonia pregunta por qué, qué le pasa. Celia reconoce: "Me desesperan!". Se refiere a "Los 38" estudiantes de su curso. Andrea evidencia: "Y pero los 38 los vas a tener en todos los temas. Cambiemos de planificación, si ésta no se adapta. Si ésta es inviable hay que hacer otra cosa". Celia posterga la decisión: "Primero seleccionar bien, y una vez que tenemos seleccionado vemos".

Esta escena ilustra los obstáculos y las indecisiones que enfrentó Celia específicamente, y todo el subgrupo de trabajo en general, al plantearse la idea de innovar en sus clases de Ciencias Naturales sobre un tema de física como es "Ondas". Las actitudes asumidas por ella a lo largo de la conversación fueron manifestaciones de sus resistencias a la propuesta, basadas 
Dumrauf, A. et al.

en preocupaciones de diverso orden: inicialmente, en el excesivo número de alumnos para una sola docente; luego, en la imposibilidad de modificar la distribución del espacio en el aula (por estar fijados al suelo los bancos); posteriormente, en la necesidad de colaboración; más tarde, en sus propias dificultades para comprender y enseñar el tema; y finalmente, volviendo al número de alumnos. Ante la explicitación de estos obstáculos, asumimos diversas estrategias de persuasión: tratamos de ofrecer alternativas tales como pensar una organización flexible del tiempo y el espacio según las necesidades y posibilidades de cada docente y grupo de estudiantes; luego buscamos dirigir la atención de las docentes hacia la - para nosotras - imprescindible selección y jerarquización de contenidos y objetivos, que a nuestro criterio, debía orientar la planificación de actividades; también evidenciamos las dificultades conceptuales involucradas en la temática "Ondas"; y finalmente, comenzamos a abordarlas, a fin de brindar un apoyo en ese aspecto a las docentes menos formadas en el área de la física. Tal abordaje fue la oportunidad para que Celia revelase sus estrategias habituales frente a la obligación programática de abordar contenidos de física: "De más está decirte que toda la parte de física la dejo para fin de año" y "Por eso yo nunca llego". Si bien el clima de confianza y colaboración ofrecido favoreció la explicitación de tales recursos, habitualmente ocultados por los y las docentes, no fue suficiente para acompañarla en su proceso de innovación. Celia asistió a algunas reuniones de trabajo más, pero no llevó a la práctica las propuestas didácticas allí elaboradas. Su actitud final fue la autoexclusión.

\section{Escena 4: La confrontación como estrategia}

En escena: nueve integrantes del equipo de trabajo (Celia, Isabel, Dora, Laura, Sandra, Carina, Miriam, Melina, Gisela) y cinco integrantes del equipo coordinador (Andrea, Sonia, Analía, Mora y Gisela).

Estamos todas en ronda comentando nuestras impresiones respecto de la reciente conferencia "El siglo ausente. Una perspectiva para pensar la enseñanza de la ciencia" brindada por un científico invitado en el marco del Proyecto. Luego de socializar aspectos relacionados con el contenido de la conferencia, pasamos, de manera informal, entre vecinas de asiento, a comentar impresiones no ya de la conferencia sino del conferencista... su forma de expresarse, su formación, los recursos que utiliza en sus charlas, etc. Una de las coordinadoras no lo conoció, porque ese día no pudo asistir; sus referencias remiten a lo que le comentaron las demás. Y dice, riéndose, que "Andrea dijo que es muy judío", como parte de una caracterización. A partir de esto ese subdiálogo comienza a generalizarse. De alguna manera el comentario desató toda una serie de intervenciones. Se enfatiza esta imagen de "muy judío" y ante el comentario de que "Todos dijeron eso, que se notaba permanentemente su origen", la coordinadora responde que le parece bien que tenga tan vivo el sentimiento, que consiga plantearlo de esa forma... queriendo dejar en claro que su comentario inicial no tuvo ninguna connotación negativa.

Sin embargo, la conversación deriva hacia observaciones estereotipadas respecto de la condición judía, de llevarlo "en un sentido positivo" o ser "resentido", de que "si vos vas dentro de una comunidad judía... heterogénea, que haya de todo... y vos hacés eje en tu condición [de no judía], te dicen que los 
discriminás a los judíos". En relación con esta última afirmación surge un comentario: "En una conferencia, me parece que no hay necesidad de decir si sos judío o sos no judío".

Las coordinadoras nos preocupamos ante el giro que ha tomado la charla. Consideramos que todos los comentarios, sobre todo el último, son discriminatorios. Andrea, entonces, por primera y única vez en su relación con las docentes aparece con actitud abiertamente contraria y frontal: "Lo que pasa es que él lo rescata y lo plantea en función de la historia, y yo creo, en eso me parece muy valioso. Porque el tema del holocausto tiene 'justificaciones científicas'. Entonces desde ahí él lo planteaba [..] como un caso, como tomó el Proyecto Manhattan y como tomó otros casos, ¿no? Me parece que es, es realmente relevante eso. Porque es rescatar la historia reciente. Que además era el planteo de él: ¿por qué el siglo ausente, el siglo XX? Porque es donde la ciencia más influyó en nuestras condiciones de vida, tanto positiva como negativamente y en las clases de ciencias lo perdimos, no está. Porque nos parece que enseñar la ciencia del siglo $X X$, es enseñar la mecánica cuántica. $Y$ no es sólo eso, ni la relatividad, que probablemente en el Polimodal no vamos a llegar ni al principio. Pero están todas estas cuestiones de uso de la ciencia, y abuso de la ciencia, que se pierden también. $Y$ un caso concretísimo es la Alemania nazi. ; Es impresionante si uno se mete! Desde las empresas, la BASF, que todos conocemos, en qué apoyó, en qué se metió, en la producción de qué elementos para el exterminio. Y es, es, yo creo que es caso paradigmático del siglo XX. Entonces, que él lo retome porque además es parte de su historia ancestral, me parece que es positivo. Y los católicos, tal vez no lo podemos tomar, porque estuvimos lamentablemente del otro lado como iglesia, apoyando del otro lado, entonces es triste no poder tomarlo... Si hubiéramos tenido a lo mejor una postura más crítica, entonces a lo mejor ahora lo podríamos reivindicar de otra manera..."

Esta escena constituyó casi el único caso en que nuestra estrategia pasó por la confrontación con integrantes del equipo. En un contexto relajado, de comentarios elogiosos sobre la conferencia escuchada, una observación risueña acerca del conferencista hecha por Sonia pareció ser un aval implícito a la expresión de discursos y estereotipos antisemitas. El surgimiento de tales comentarios, inesperados y distantes del marco ideológico que consideramos deseable, evidenció otro límite no negociable: los valores de respeto y tolerancia. Ello desencadenó una explicitación de nuestra postura, referida al caso específico, pero que claramente era un mensaje a las docentes acerca de toda forma de discriminación. En síntesis, en esta escena surge inesperadamente una clara tensión - en la expresión de valores contrapuestos- que se resuelve a través de una confrontación abierta.

\section{Escena 5: La colaboración}

En escena: dos docentes (Carina y Laura) y tres coordinadoras (Mora, Andrea y Analía)

Estamos en una reunión de trabajo con el subgrupo que había comenzado la planificación de un taller sobre el "Proyecto Genoma Humano". Laura había 
Dumrauf, A. et al.

comprado varios libros vinculados al tema para preparar el taller. En una reunión previa, los había compartido con Carina. Se dividieron la lectura de los mismos y habían diseñado una primera propuesta de taller. Según sus propios dichos, habían dedicado mucho tiempo a la lectura y les costaba seleccionar los textos disparadores para el debate en el taller. Entre ambas, relatan su propuesta:

Carina: ¿Querés hablar vos Laura? porque yo tomo la palabra acá como...

Laura: No, no, prefiero que hables, yo te apunto.

Carina: No, vos, vos hablá también tranquila, entre las dos lo hicimos.

Laura: Sí, sí.

Comienza a exponer sus ideas Carina: "Habíamos dicho que íbamos a seleccionar casos puntuales [...] que plantearan dilemas éticos a partir del proyecto. Bueno, ehhhmm, la idea era, por ejemplo, tomar el tema del patentamiento de genes. Eh, Laura tiene un artículo que habla sobre el patentamiento del gen del cáncer de mama". Continúa comentando sus lecturas Laura: "Sí, que lo patentó la empresa privada, Celera Genomics [...] Los dos genes que patentaron. $Y$ patentaron el uso y después toda la terapia farmacológica derivada también". La conversación se deriva con el comentario de Mora hacia la compra de empresas biotecnológicas por grandes laboratorios. Carina retoma la presentación de sus ideas: "Bueno, en función de ese, de ese tema, del patentamiento y el... y el ver quiénes van a tener acceso a esa información [...] pensábamos que planteando el dilema del patentamiento, podemos, cuando les demos los textos para leer, podríamos darles el capítulo que habla sobre este tema como para dar un marco teórico al dilema ¿o no? ¿Sería algo así?". Entre las dos redondean la idea:

Laura: "Claro, es como a algún grupo darle..."

Carina: "...Como que clarifique".

Laura: "... el artículo del patentamiento éste eh, en manos privadas y después..."

Carina: "La otra cuestión, que sería la de Sulston"...

Laura: "Y le anexamos el texto éste"...

Carina: "Que sería un elemento más para poder reflexionar sobre el tema".

Andrea refuerza la propuesta, evaluando que sería el debate desde dos perspectivas: "Una patentarlo, otra no patentarlo". Carina explicita que le cuesta estructurar el taller "lo voy pensando en función de seleccionar un dilema y ver qué les podemos dar como para que lean en función de ese dilema. Para tratar de tener más herramientas para poder discutir, o tomar una decisión, o ponerse en blanco, no sé. ¡Crear opinión!". Laura imagina que "se pueden dar las dos posturas dentro del grupo". Carina vuelve al tema del patentamiento y el surgimiento, en torno a él, de las posturas que defienden "lo público y lo privado en el contexto del proyecto". "Y el control de la información", completa Laura. Entre ambas comentan la lectura de un texto en el que se discuten los beneficios del acceso público a la información genética y los obstáculos que pondría la empresa privada. Finalmente, plantean que "el otro dilema sería el derecho a conocer y a no conocer. $Y$ ahí plantearíamos un caso. Que el caso es el que dijimos la vez pasada, el paciente con ALD". 
Esta escena muestra el funcionamiento de este subgrupo de trabajo, iniciado por Carina y Laura y al que posteriormente se incorporaron Mora y Gisela. Las integrantes no sólo explicitan que han armado su propuesta "entre las dos". También de esa manera construyen el texto del relato y su taller. La colaboración parece ser una característica del funcionamiento de este subgrupo, atributo que se reflejó en el diseño, la planificación y la puesta en práctica del taller. En la implementación del mismo participaron las cuatro integrantes asumiendo distintos roles en diferentes momentos. Por otro lado, en el inicio del análisis de esta implementación, entre los elementos de partida que las docentes evaluaron como favorables para su desarrollo, destacaron: "confianza y respeto; buena disposición para el trabajo; compromiso; horizontalidad en las ganas de aprender; el poder, nadie era EL que sabía y dominaba la situación” (MARTÍNEZ et al., 2007).

\section{Reflexiones sobre la experiencia}

En este recorrido de escenas nos vimos, como coordinadoras, asumiendo frecuentemente estrategias de persuasión, con el fin de sostener la - para nosotras innegociable - continuidad del proyecto. Leímos las actitudes de resistencia de algunas docentes, no sólo como el miedo a la pérdida que involucra el cambio, sino también como una manifestación de su desconocimiento de alternativas didácticas que consideraran viables en sus contextos. Por ello, en dicho camino de persuasión intentamos ofrecer aportes teóricos y metodológicos a partir de lecturas de materiales específicos y de nuestros conocimientos y experiencias; regular el nivel de autoexigencia de las docentes involucradas; estimular sus iniciativas; discutir empáticamente sus frecuentes sensaciones de impotencia y, en todo momento, respetar sus decisiones.

Escasísimas fueron las instancias de abierta confrontación entre nosotras y el resto del equipo de trabajo (en nuestros registros sólo dos: una, presentada en la escena 4; otra, con una participante, que finalmente se desvinculó del proyecto). A pesar de haber disensos respecto de cuestiones conceptuales, pedagógicas e ideológicas, sólo en una ocasión establecimos un límite claro a la expresión de posturas que consideramos abiertamente intolerantes. Como dice Freire (2002a, p. 64-5): "Sin [la tolerancia] es imposible realizar un trabajo pedagógico serio, sin ella es inviable una experiencia democrática auténtica; sin ella la práctica educativa progresista se desdice [...]. El acto de tolerar implica el clima de establecer límites, de principios que deben ser respetados”. Nuestra estrategia general apuntó a

[...] colocar preguntas, o ejemplos o imágenes que susciten la reflexión sobre lo dicho, de tal manera que las contradicciones contenidas en lo dicho, así como sus aspectos injustos, falaces y negativos para esa misma persona o para grupos con los cuales ella trate, queden de manifiesto. La pregunta o imagen problematizadoras actúan como estímulos disparadores de la reflexión crítica. No se trata de imponer una nueva visión que desde nuestra posición juzgamos correcta, forzando su aceptación por el otro, sino de suscitar en ese otro un proceso de análisis, comprensión y transformación en el cual esa persona es la actora fundamental. (MONTERO, 2007, p. 225-6) 
Las resistencias de las docentes se vincularon, explícitamente, a obstáculos de diverso orden: el número de alumnos, las dificultades edilicias, la falta de materiales, la rigidez de la estructuración temporal de las clases, la falta de entusiasmo, las dificultades para armar grupos de trabajo. La interpretación de las escenas, sumada a la relectura de la base general de información, nos llevó a elaborar una hipótesis respecto de los motivos de autoexclusión de algunas de las docentes: en un caso fue explícita la inseguridad en el manejo de contenidos específicos de las ciencias naturales; en otros, a través de la descalificación, las docentes estarían mostrando su rechazo a nuestra intervención como colaboradoras en la elaboración y análisis de propuestas áulicas.

El funcionamiento colaborativo, como característica grupal, se manifestó claramente en dos de los subgrupos de trabajo - uno de ellos presentado en la escena 5. La colaboración fue facilitada en ambos casos por el conocimiento mutuo, el trabajo previo de algunas de las integrantes y la confluencia de intereses y expectativas en el proyecto. Dicha característica se evidenció en la asunción comprometida y compartida de la tarea.

Para analizar las diversas actitudes y estrategias presentadas podemos recurrir a las categorías de Branco (1998) en su caracterización de los funcionamientos grupales. Esta autora enfatiza el carácter dinámico de las complejidades implicadas en los procesos de interacción social y propone el término "orientación” sugiriendo la dirección de las acciones de una persona, que emergen continuamente, fluctúan y cambian, entrelazadas con el contexto de las acciones en proceso. Partiendo de esa noción, Branco elabora las categorías teóricas de 'convergencia', 'divergencia y negociación' de las orientaciones de objetivos individuales, dentro de contextos culturalmente estructurados. Estos conceptos permiten, según la autora, expresar la cualidad dinámica y procesual de los fenómenos de interacción. En la 'convergencia' de las orientaciones existe compatibilidad (y no indiferenciación) entre las orientaciones de objetivos de los participantes, inferida a partir de sus actitudes. La 'convergencia' ofrece una base relativamente estable para los esfuerzos comunicativos y lleva a cierta consistencia en la interacción, lo cual permite la construcción activa de la intersubjetividad entre los participantes. La incompatibilidad de orientaciones de objetivos, característica de la 'divergencia', significa que éstos no pueden ser realizados al mismo tiempo. $\mathrm{Y}$ el proceso que permite el movimiento entre convergencia y divergencia es llamado, en este marco, 'negociación' (CORDERO, 1999).

Las escenas presentadas podrían analizarse, atendiendo a esta categorización, como manifestaciones de la convergencia o divergencia en las orientaciones de objetivos de las participantes. Nuestra actividad como coordinadoras se leería como un proceso de negociación que pretendía mover la interacción hacia la convergencia de orientaciones.

Por otro lado, siguiendo a Duschatzky y Corea (2004), podríamos interpretar la resistencia como una expresión del desacople entre "representaciones viejas" y situaciones actuales. "La resistencia es en definitiva una resistencia a pensar, a poner en suspenso categorías abstractas o a declarar que fueron eficaces en otras condiciones sociohistóricas [...] es una negación a cambiar las preguntas y a dejarnos alterar por los signos de lo nuevo" (DUSCHATZKY y COREA, 2004, p. 88-9). Las autoras presentan como enemigo de la educación a la "idea de lo definitivo, de la determinación, de la impotencia, de la irreversibilidad". Como alternativa rescatan la categoría de invención que "supone producir singularidad, esto es formas inéditas de operar con lo real que habiliten nuevos modos de habitar una situación y por ende de constituirnos como sujetos" (DUSCHATZKY y COREA, 2004, p. 89-90). Consideramos que toda la experiencia del proyecto de investigación colaborativa se inscribiría en esta 
categoría de 'invención', en tanto nos ha permitido constituirnos como sujetos en situación, como actoras capaces de transformar, en alguna medida, nuestra realidad educativa. Así, la creación de escenarios institucionales, la superación concreta de algunas resistencias y la implementación de propuestas didácticas novedosas tanto para las docentes como para la institución, estarían dando cuenta de - al menos para nosotras y en nuestro contexto - nuevas formas de operar con lo real, de la posibilidad de superar las ideas de 'impotencia y determinación'.

Desde otra perspectiva, una relectura de las actitudes y estrategias descritas, intentando develar el carácter político de la trama vincular establecida, debería reconocer las desigualdades que atraviesan al grupo con relación a la posesión de saberes/poderes y a la adjudicación/ asunción de posiciones sociales/institucionales. En particular, nos referimos a la posición jerárquicamente superior otorgada/asumida por las personas que procedemos de la universidad, en razón de los saberes que supuestamente portamos y a nuestro rol de académicas-investigadoras validadas socialmente. En la relectura de las diversas instancias de interacción con el grupo completo y con los diversos subgrupos de trabajo, percibimos, en este sentido, la manifestación de dos tipos de expectativas: una, de "transferencia" de nuestros saberes, asumiendo de manera tradicional el rol de formadoras, y otra, de validación de la propia actuación, a través de la expresión de nuestro reconocimiento a sus prácticas áulicas habituales. Desde la formulación del proyecto, nuestra intención fue democratizar los vínculos jerárquicos socialmente instalados e intentar conformar un espacio de diálogo en el cual construir propuestas didácticas a partir de la contribución de todas las participantes, aceptando que podíamos aportar conocimientos diferenciados, pero igualmente valiosos (FREIRE, 1993). Analizando las escenas presentadas y los vínculos establecidos con los diversos grupos de trabajo, consideramos que esta intención pudo concretarse sólo en algunos casos. En el caso del vínculo con el grupo presentado en la escena 5, nuestro deliberado corrimiento promovió la colaboración grupal y el enriquecimiento personal de sus integrantes. Con el grupo de la escena 1 mantuvimos, hasta su disolución, una compleja relación en la que percibimos un juego entre la exigencia de propuestas y su descalificación sistemática. Entendemos que este tipo de relación, que no pudimos modificar, manifestaría una forma más conflictiva de sostenimiento del vínculo jerárquico: la puesta a prueba de una supuesta autoridad y descalificación subsiguiente - ejercida por una parte y aceptada por la otra - sin poder cuestionar los lugares sociales de cada una para transformarlos. En otro caso, no presentado en las escenas anteriores, la jerarquía se sostuvo a través de un proceso en el cual los roles de formadoras "tradicionales" - es decir, "dadoras" de saber y evaluadoras de la producción - no fueron cuestionados por ninguna de las participantes.

\section{Consideraciones finales: aprendizajes para la próxima "puesta en escena"}

Este ejercicio de autoanálisis, de relecturas y de resignificación de vieja y nueva bibliografía, luego de la experiencia vivida y narrada, nos ha permitido vislumbrar una serie de dimensiones en las que fuimos construyendo diversos aprendizajes. Dichas dimensiones son señaladas por diversos autores, pero fue la vivencia, el "ir haciendo/pensando", lo que nos hizo otorgarle nuestros propios sentidos.

En principio, reconocimos que, como dice Montero (2007), la problematización es un proceso total, y no sólo una etapa de la investigación colaborativa, y que, además involucra 
Dumrauf, A. et al.

a todas las y los participantes en este tipo de investigación. De acuerdo con Freire (1997, p. 94) en relación con los procesos de formación:

la tarea del educador [...] es la de problematizar a los educandos, el contenido que los mediatiza, y no la de disertar sobre él [...] En este acto de problematizar a los educandos, él se encuentra igualmente problematizado. La problematización es a tal punto dialéctica que sería imposible que alguien la estableciera sin comprometerse con su proceso.

Nuestras representaciones y nuestros saberes, tanto como formadoras de docentes, cuanto como investigadoras, se vieron interpelados por esta experiencia de trabajo colaborativo. Aprendimos que nuestra dominante estrategia de persuasión fue fructífera en algunos casos y promovió el desarrollo de iniciativas pero, en otros, al menos no favoreció el compromiso, la participación ni la democratización de las relaciones. En la reformulación de la propuesta, para su ampliación a un mayor número de establecimientos y docentes, consideramos necesario revisar nuestras estrategias de intervención. Creemos que la asunción de un rol crítico más explícito desde la coordinación podría estimular la revisión de representaciones obstaculizadoras del proceso de innovación.

También nos dimos cuenta que, tanto la criticidad cuanto la autonomía - para nosotras y el resto de las participantes - nos han resultado dificultosas construcciones. En este sentido, funcionaron como horizontes.

Nadie es autónomo primero para después decidir. La autonomía se va constituyendo en la experiencia de varias, innumerables decisiones que van siendo tomadas [...] La autonomía en cuanto maduración del ser para sí es proceso, es llegar a ser [...]. Es, en este sentido en que una pedagogía de la autonomía tiene que estar centrada en experiencias estimuladoras de la decisión y de la responsabilidad, valga decir, en experiencias respetuosas de la libertad. (FREIRE, 1997, p. 103)

Finalmente, el espacio funcionó para todas las participantes como una instancia de "formación situada", en la que problematización, indagación y reflexión fueron planteadas sobre situaciones concretas construidas por nosotras mismas. En este sentido, acordamos con Freire (1973, p. 95) en que

La problematización es inseparable de las situaciones concretas. Ésta es la razón por la cual, partiendo de estas últimas, cuyo análisis lleva a los sujetos a reverse en su confrontación con ellas, a rehacer esta confrontación, la problematización implica un retorno crítico a la acción. Parte de ella y a ella vuelve. En el fondo, en su proceso, es la reflexión, que alguien ejerce sobre un contenido fruto de un acto o sobre el propio acto, para actuar mejor con los demás.

Nuestra próxima "puesta en escena", nuestro "retorno crítico a la acción”, tiene como punto de partida las vivencias y reflexiones narradas en este trabajo. Sabemos que no retorna- 
La "cocina" de una investigación ...

remos las mismas y que encontraremos nuevos desafíos. También sabemos que no podemos "transmitir" nuestras experiencias/vivencias/reflexiones a otros investigadores e investigadoras que transiten caminos similares. Sin embargo, estamos convencidas de que, al abrir la puerta de nuestra "cocina", presentar nuestros "escenarios", "escenas" y algunos "ensayos" de la puesta en escena ya vivida, aportamos, por un lado, a la construcción de "teorías locales" pertinentes "para las comunidades interpretativas en que se producen y claves para reorientar la acción" (TORRES y CENDALES, 2006, p. 36). Por otro, al compartirlas con la comunidad de docentes e investigadores, pretendemos contribuir también al debate respecto a la relación investigación crítica-transformación social.

\section{Referencias}

ACHILLI, E. Investigación y formación docente. Rosario: Laborde Editor, 2004.

BARCELOS, N. N. S.; VILLANI, A. Troca entre universidade e escola na formação docente: uma experiência de formação inicial e continuada. Ciência \& Educação, Bauru, v. 12, n. 1, p. 73-97, 2006.

BOGGINO, N.; ROSEKRANS, K. Investigación-acción: reflexión crítica sobre la práctica educativa. Orientaciones prácticas y experiencias. Rosario: Homo Sapiens, 2004.

BOLÍVAR BOTÍA, A. ¿’De nobis ipsis silemus”?: epistemología de la investigación biográfico narrativa en educación. Revista Electrónica de Investigación Educativa, México, v. 4, n. 1, p. 40-65, 2002.

BRANCO, A. Cooperation, competition and related isssues: a co-constructive approach. In: VALSINER, J.; LYRA, M. C. D. P. (Eds.). Construction of psychological processes in interpersonal communication: contemporary studies in child development within culturally structured environments. Connecticut: Ablex Publishing Corporation, 1998. v. 4, p. 181-205.

COLL, C. et al. Los contenidos en la reforma: enseñanza y aprendizaje de conceptos, procedimientos y actitudes. Madrid: Aula XXI, Santillana, 1992.

CORDERO, S. Aprender com outros: um estudo das interações entre alunos em aulas universitárias de Física. 1999. 255f. Dissertação (Mestrado) - Programa de Pós-Graduação em Educação. Universidade Federal Fluminense, Niterói, 1999.

DOS SANTOS ROSA, M. I.; PACHECO SCHNETZLER, R. A investigação-ação na formação continuada de professores de ciências. Ciência $\boldsymbol{\&}$ Educação, Bauru, v. 9, n. 1, p. 27-39, 2003.

DUMRAUF, A. Investigación colaborativa para la reconstrucción de prácticas y la innovación en la educación en ciencias naturales. Proyecto de Investigación Científica y Tecnológica Orientado a la Educación (PICTO Educación No 18-36034). Argentina: Agencia Nacional de Promoción Científica y Tecnológica, 2005a.

Curriculum y prácticas de enseñanza en la educación en ciencias naturales. Proyecto de Investigación y Desarrollo 11/H409. Argentina: Universidad Nacional de La Plata, 2005b. 
Dumrauf, A. et al.

DUSCHATZKY, S.; COREA, C. Chicos en banda: los caminos de la subjetividad en el declive de las instituciones. Buenos Aires: Paidós, 2004.

ELLIOT, J. La investigación-acción en educación. Madrid: Morata, 1994.

FREIRE, P. Cartas a quien pretende enseñar. Buenos Aires: Siglo XXI, 2002a.

Pedagogía del oprimido. Buenos Aires: Siglo XXI, 2002b.

Pedagogía de la esperanza. México: Siglo XXI, 1993.

Pedagogía de la autonomía. México: Siglo XXI, 1997.

FREIRE, P. ¿Extensión o comunicación? La concientización en el medio rural. México: Siglo XXI, 1973.

FREITAS PETRUCCI, M. I. et al. Formação de professores da área de ciências sob a perspectiva da investigação-ação. Revista Brasileira de Pesquisa em Educação em Ciências, Belo Horizonte, v. 3, n. 1, p. 58-69, 2003.

MARTÍNEZ, C. et al. Los dilemas éticos del proyecto genoma humano: una experiencia de innovación y trabajo colaborativo. Actas Jornadas Enseñanza e Investigación Educativa Ciencias Exactas y Naturales, La Plata, Sec. Naturales, p. 65-71, 2007.

MESSINA, G. Investigación en o investigación acerca de la formación docente: un estado del arte en los noventa. Revista Iberoamericana de Educación, Madri, n. 19, p. 145-207, 1999.

MONTERO, M. La problematización como aspecto crítico en el proceso de liberación. In: DOBLES OROPEZA, I.; BALTODANO ARRÓLIGA, S.; LEANDRO ZÚÑIGA, V. (Eds.). Psicología de la libración en el contexto de la globalización neoliberal: acciones, reflexiones y desafíos. San José de Costa Rica: Universidad de Costa Rica, 2007. p. 216-29.

PEREIRA DOS SANTOS, W. L. et al. Formação de professores: uma proposta de pesquisa a partir da reflexão sobre a prática docente. Ensaio - Pesquisa em Educação em Ciências, Belo Horizonte, v. 8, n.1, p. 1-14, 2006.

PICHON-RIVIÈRE, E. E1 proceso grupal: del psicoanálisis a la psicología social (1). Buenos Aires: Nueva Visión, 1985.

SÁNCHEZ PILONIETA, A. Dispositivos de empoderamiento para el desarrollo psicosocial. Universitas Psicológica, Bogotá, v. 1, n. 2, p. 39-48, 2002.

TORRES, A.; CENDALES, L. La sistematización como experiencia investigativa y formativa. La Piragua, Panamá, n. 23, p. 29-38, 2006.

TORRES CARRILLO, A. La sistematización como investigación interpretativa crítica: entre la teoría y la práctica. In: SEMINARIO INTERNACIONAL SOBRE SISTEMATIZACIÓN Y PRODUCCIÓN DE CONOCIMIENTO PARA LA ACCIÓN, 1996, Santiago. Conferencia... Santiago, 1996. Disponível em: < http://www.alforja.or.cr/ sistem/cgi-bin/blosxom.cgi/reflexionteorica>. Acesso em: 21 nov. 2006.

Artigo recebido em julho de 2008 e aceito em fevereiro de 2009. 